\title{
Endoscopic treatment of carpal tunnel syndrome: a critical review
}

\author{
David F. Jimenez, M.D., Scott R. Gibbs, M.D., and Adam T. Clapper, B.S. \\ Division of Neurosurgery, University of Missouri Hospital and Clinics, Columbia, Missouri
}

An extensive review of published articles on the subject of endoscopic carpal tunnel release surgery is presented, encompassing six endoscopic techniques used to treat carpal tunnel syndrome. Since the first report in 1987, 7091 patients have undergone 8068 operations. The overall success rate has been $96.52 \%$, with a complication rate of $2.67 \%$ and a failure rate of $2.61 \%$. The mean time to return to work in patients not receiving Workers' Compensation was 17.8 days, ranging between 10.8 and 22.3 days. The most common complications were transient paresthesias of the ulnar and median nerves. Other complications included superficial palmar arch injuries, reflex sympathetic dystrophy, flexor tendon lacerations, and incomplete transverse carpal ligament division. All studies in which open and endoscopic techniques were compared reported that patients in the latter group experienced significantly less pain and returned to work and activities of daily living earlier. The reported success and complication rates of endoscopic carpal tunnel release surgery are similar to those for standard open procedures. Endoscopic techniques and outcomes are discussed.

\section{Key Words * carpal tunnel * endoscopy * carpal ligament}

Following the introduction of endoscopic techniques for treatment of carpal tunnel syndrome (CTS) in the late 1980s, significant controversy ensued regarding the efficacy, safety, and success of these procedures. Numerous reports have been published, mostly in the orthopedic and plastic surgery literature, describing modifications to the original procedure as well as results and complications. To date, no such publication has appeared in the neurosurgical literature. The goal of this paper is to present neurosurgeons with a comprehensive and critical review of the endoscopic procedures currently in use for the treatment of CTS.

\section{HISTORY OF CARPAL TUNNEL SYNDROME}

In 1854, Paget[51] was the first to describe a condition affecting the median nerve in a patient following a fracture of the distal third of the radius. A report by Putnam in 1880[61] alluded to symptoms consistent with CTS in several patients. In 1909, Hunt described "thenar and hypothenar types of neural atrophy of the hand." In 1911 he described three patients with thenar atrophy, whose characteristics led him to hypothesize that the lesion was located at the "thenar branch of the median nerve . . as it passes over the palmar border of the anterior annular ligament."[27] In 1913 French neurologists Marie and Foix[38] described a patient with thenar atrophy secondary to interstitial neuritis at the level of the transverse carpal ligament (TCL) causing strangulation of the nerve beneath the ligament and a neuroma above it. Learmonth,[32] in 1933, was the first to describe the surgical release of the TCL to treat 
posttraumatic median nerve compression. In 1941, Woltman,[73] used Learmonth's technique to treat two patients with thenar palsy, one with acromegaly and the other with arthritis of the wrist. In 1945, Zachary,[75] an orthopedist, reported on the surgical release of an entrapped median nerve in two patients: one patient had an untreated Colles' fracture and the second a pseudocyst. In 1946, Cannon and Love[12] were the first to use release of the TCL in patients suffering nontraumatic compression of the median nerve. However, it was not until 1947 that the British neurologist Brain[8] wrote the first detailed manuscript describing the pathophysiology of spontaneous nerve compression at the wrist. In that classic paper, he also outlined the surgical treatment for nontraumatic compression of the median nerve in six patients. Thereafter, the concept of CTS was popularized. In 1950 and over the following two decades, Phalen[55-60] reported on a large number of patients with idiopathic spontaneous CTS, treated by surgical transection of the ligament and single-handedly popularized this approach. Open carpal tunnel release (CTR) surgery became the standard procedure to treat this syndrome.

\section{ENDOSCOPIC PROCEDURES}

The impetus for the use of endoscopes in hand surgery began in the early part of this century when Takaji (as cited in Chow [14]) successfully placed the first endoscope in a knee to examine the joint. Since the introduction of the first endoscopic procedure to transect the TCL in 1987,[47] several modifications have been described. These techniques are divided into two major categories. Single-portal techniques are those in which a single incision is made in the proximal wrist. Dual-portal techniques are those in which, in addition to the proximal incision, a second small incision is made in the palm. The following sections will provide a summary of all the procedures as they have been described in the literature.

\section{SINGLE-PORTAL TECHNIQUES}

\section{The Okutsu Technique}

In 1987, Okutsu, a Japanese orthopedist, first reported the use of an endoscope to incise the TCL in patients with CTS.[47] He developed a system called "The Universal Subcutaneous Endoscope System." His technique involved making a $2-\mathrm{cm}$ incision in the distal forearm $3 \mathrm{~cm}$ proximal to the distal wrist crease (Fig. 1). Following dissection through the antebrachial fascia, an obturator was introduced under the fascia and into the carpal tunnel. Originally, the technique called for removal of the obturator, followed by insertion of a clear cylindrical plastic tube radial to the palmaris longus tendon. A rigid 30š angle endoscope was inserted into the clear plastic tube to visualize the various anatomical structures. The endoscope was withdrawn and then inserted in the ulnar aspect of the palmaris longus tendon. That technique was modified in 1989 by Okutsu[45,46] so that the endoscope was inserted once and only on the ulnar side of the palmaris longus. A hook probe was used to clear and move away any portion of the flexor tendon before transecting the TCL. A retrograde hook knife introduced alongside (ulnar aspect) the plastic sheath was used under direct visualization to incise the TCL distally to proximally. The incision was closed in standard fashion. Although patented in the United States, The Universal Subcutaneous Endoscopic System (which was "handmade" by the author) never became commercially available. 


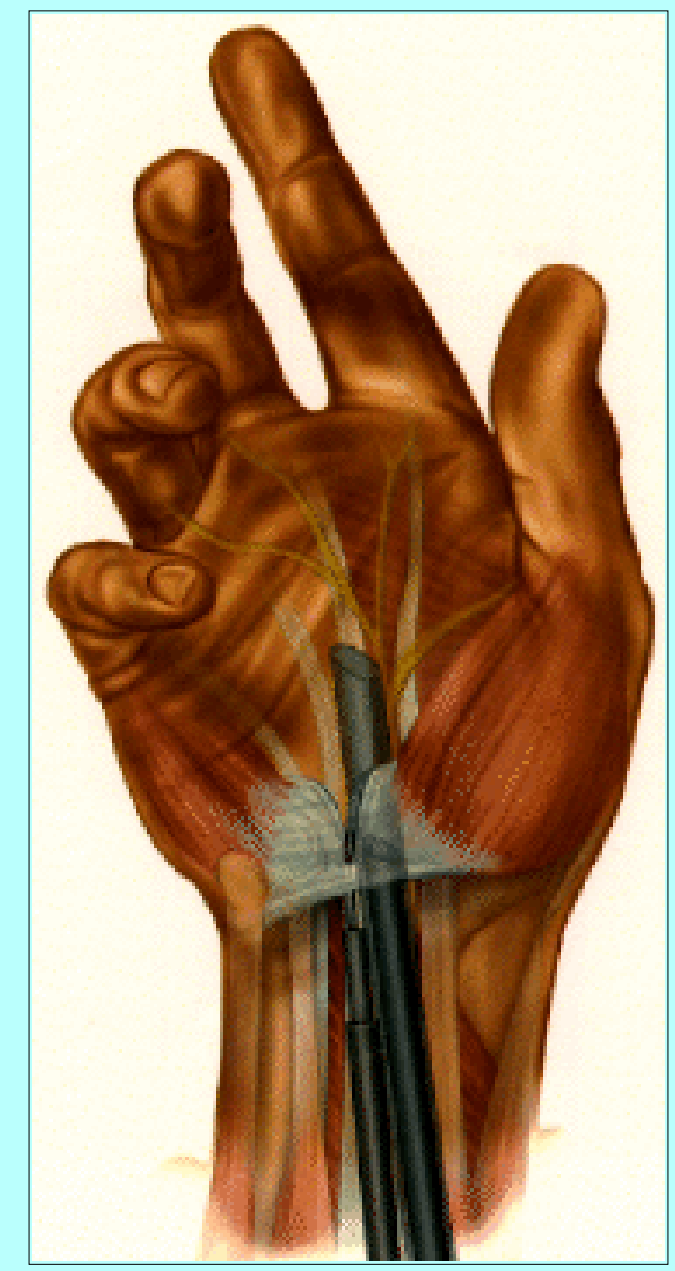

Fig. 1. Artist's illustration depicting Okutsu's monoportal technique. An incision is made 3 $\mathrm{cm}$ proximal to the distal wrist crease. A clear plastic cannula is inserted into the carpal tunnel with an angled endoscope inside. Under direct visualization, the TCL is incised distally to proximally with a hook knife.

\section{The Agee Technique}

In 1990, John Agee and Francis King, in conjunction with the 3M Corp. (3M Orthopedic Products Division, St. Paul, MN), developed an endoscopic device to release the TCL at the Hand Biomechanics Laboratory in Sacramento, California.[3] The system was composed of a video endoscope and a pistol-grip hand piece (with an integral trigger mechanism) coupled to an endoscope-blade assembly that was inserted into the carpal tunnel (Fig. 2). A window located near the tip of the assembly allowed viewing of the undersurface of the TCL through the endoscope. The entire assembly was inserted through a $3-\mathrm{cm}$ incision in a wrist flexor crease. A trigger-activated mechanism allowed a triangular blade to engage and elevate $3.5 \mathrm{~mm}$ above the surface of the assembly. Once the blade was engaged, the entire unit was retracted, thereby cutting the TCL. A flaw in the design of this instrument was that the endoscopic window was located proximal to the blade-elevating mechanism and the blade's point of entry into the tissue could not be visualized. After a number of vascular, neural, and tendinous injuries occurred using the device, 3M Corp., withdrew the system from the market late in 1990. In 1992, following a redesign of the blade assembly, 3M Corp., reintroduced the instrument with modifications that allowed the surgeon to see the blade as it entered the tissue.[2] 


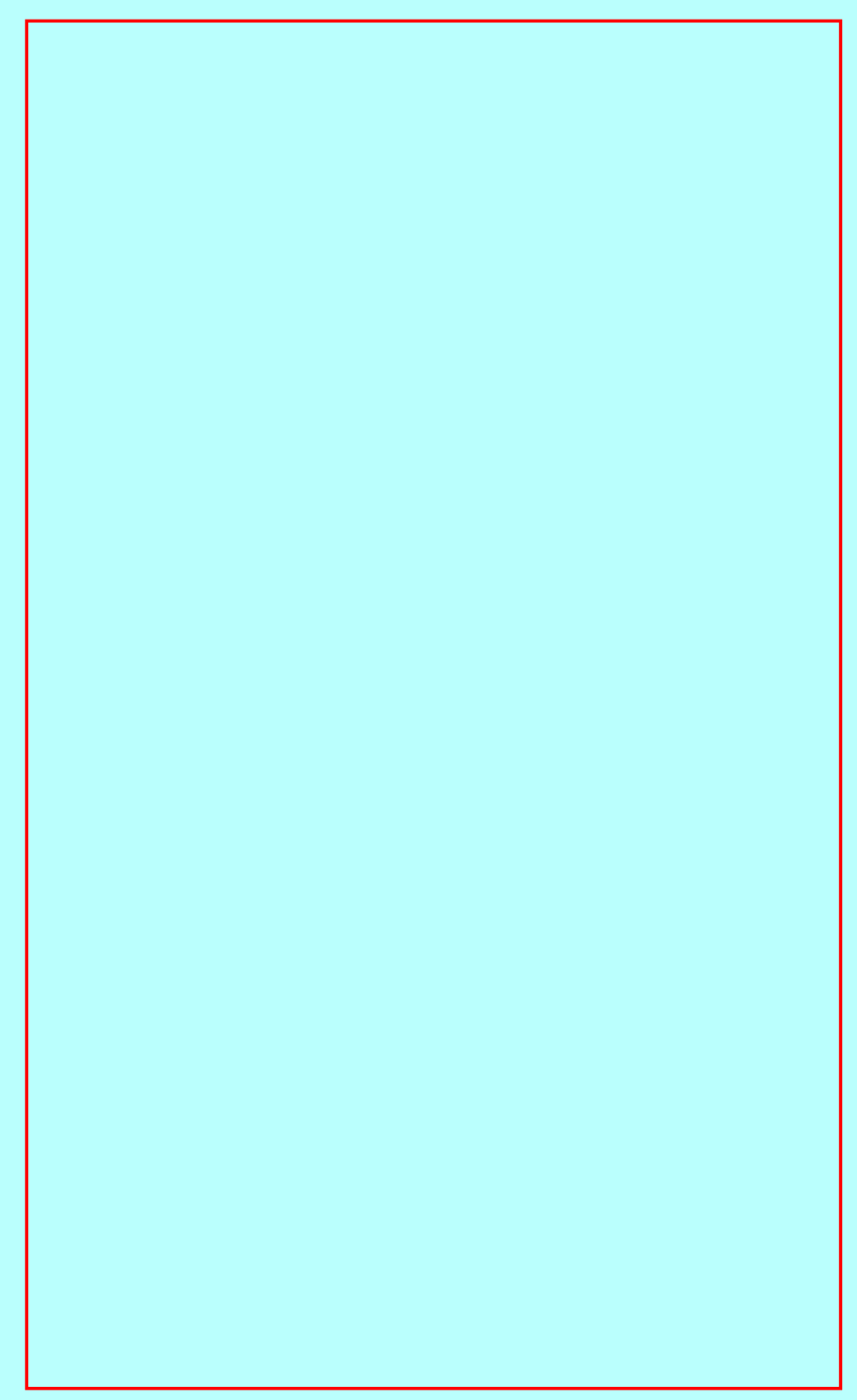

Fig. 2. Artist's illustration showing Agee's monoportal technique. A distal forearm incision is made to allow passage of the endoscope-cannula assembly into the carpal tunnel. The blade is located at the distal end of the cannula along with the endoscope. After the blade has been activated, the entire unit is retracted in a distal to proximal direction, thereby cutting the TCL.

\section{The Modified Agee Technique}

The following is a description of the technique recommended for use with the redesigned unit. Following exsanguination of the arm and inflation of a tourniquet, a 2- to 3-cm incision is made in one of the wrist flexion creases between the flexor carpi ulnaris and flexor carpi radialis muscles. Subcutaneous longitudinal dissection exposes the antebrachial fascia. A U-shaped incision is made on the antebrachial fascia, creating a rectangular flap distally based on the TCL. While the flap is elevated, a synovial elevator is placed under the TCL and aimed at the base of the fourth finger. A hamate finder is inserted into the carpal tunnel to create a path for the blade assembly; care is taken to "hug" the hook of the hamate on its radial side. The blade-endoscope assembly is then inserted into the carpal tunnel and passed distally to the far end of the TCL. Several passes are usually required to obtain adequate definition of the TCL. After the distal end of the ligament is defined, the tip of the instrument (along with the blade) is placed distal to the edge of the TCL. Once correct positioning is verified, the trigger 
mechanism is activated and the blade is engaged and elevated $3.5 \mathrm{~mm}$ above the assembly at an $80 \check{s}$ angle. The instrument is withdrawn, and under direct visualization, the TCL is divided in a distal to proximal direction. With the blade retracted, several passes can be made to verify transection of the ligament. If necessary, the blade may be engaged and remnants of the TCL can be divided. A proximal volar fasciotomy is then performed followed by standard wound closure.

\section{Menon's Monoportal Technique}

In 1993, Jay Menon,[41] an orthopedist at Loma Linda University, developed the Carpal Tunnel Relief Kit (Linvatec, Largo, FL) for use in a single-portal approach to CTR surgery. This system includes a cannula with a D-shaped cross-section and an obturator. The cannula's end is closed and blunt. The knife used for transecting the TCL has a central concave cutting edge with blunt corners. Two dilators $(5 \mathrm{~mm}$ and $7 \mathrm{~mm}$ ) are used to create room for the cannula inside the carpal tunnel. This technique uses a set of external landmarks to localize the palmar margin of the TCL. A 1- to 2-cm oblique incision is made toward the ulnar side, beginning at the distal wrist crease, over the palmaris longus tendon. The fibers of the antebrachial fascia are exposed and split with tenotomy scissors. The opening of the fascia is enlarged using blunt dissection. A small elevator is placed under the TCL and its undersurface is scraped to remove the synovium. After slight wrist extension, an obturator is inserted into the carpal tunnel. The length to which the obturator is inserted into the carpal tunnel is measured using external anatomical landmarks. The carpal tunnel is then dilated with 5- $\mathrm{mm}$ and 7-mm blunt dilators. The extent of dilator introduction is also measured from external anatomical landmarks.

The obturator is inserted into the cannula and the cannula, aligned with the fourth digit, is introduced into the carpal tunnel (Fig. 3). Care is taken not to advance the cannula too far into the palm as this maneuver can cause injury to the arterial palmar arch. A 30š angle, 4-mm arthroscope is inserted into the proximal end of the cannula and the TCL is visualized. The author recommends inserting a 25 -gauge needle through the skin at a point mark in the distal end of the TCL. A forward-facing knife is inserted and the TCL is incised proximally to distally. The endoscope follows immediately behind the knife to aid in visualization throughout the transection. The 25-gauge needle alerts the surgeon of the distal end of the TCL. A typical "giving away" of the knife is felt when the distal fibers are incised. A probe can be used to palpate the cut ends of the TCL. Several passes can be made to assure full transection of the ligament. The wound is closed in the standard fashion and the patient's hand is placed in a volar splint for 1 week.[40] 


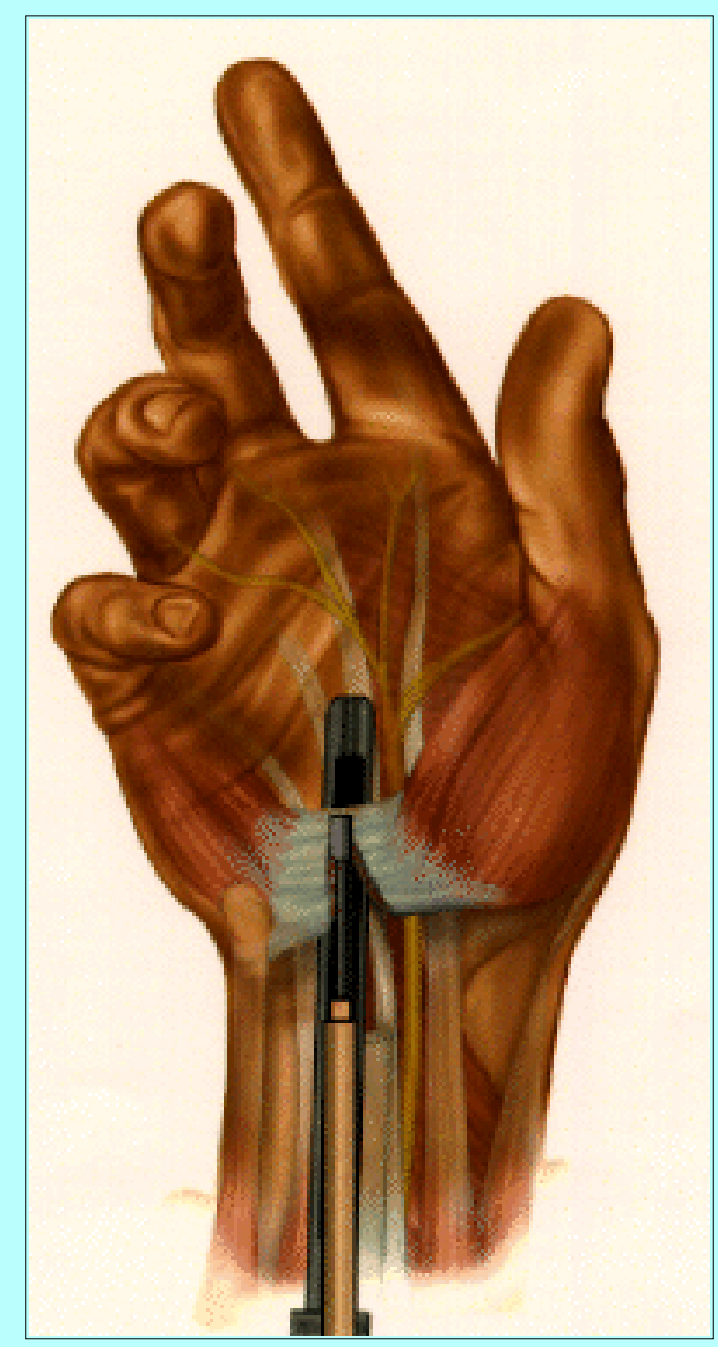

Fig. 3. Artist's illustration depicting Menon's monoportal technique. Following insertion of dilators through the antebrachial fascia into the carpal tunnel, a cannula is passed under the TCL. A forward knife is used to cut the ligament proximally to distally as the endoscope immediately follows the knife, visualizing the TCL.

\section{Worseg's Uni-Cut Technique}

Worseg's[74] Uni-Cut Carpal Tunnel Release Kit (Acufex Microsurgical Inc., Harrogate, UK) was introduced in 1996 and consists of five disposable instruments including a bursal elevator, blunt-tipped channeler $(6.5 \mathrm{~mm}$ at one end and $10 \mathrm{~mm}$ at the other), an angled probe with a right-angled tip, a dual-slotted cannula, and an angled hook knife. A $1.5-\mathrm{cm}$ transverse incision is made proximal to the volar wrist crease in an ulnar direction to the palmaris longus tendon. Following exposure and incision of the antebrachial fascia, a small blunt retractor is used to dissect the bursal tissue from the undersurface of the TCL. Next, the 6.5-mm end of the channeler is used to dilate the area around the hook of the hamate. The dual-slotted cannula is inserted with the slotted portion directly against the undersurface of the TCL. A 2.7-mm 30š-angled endoscope is used to visualize the undersurface of the TCL. A hook knife is inserted proximally and advanced into the palm immediately past the distal end of the TCL. The knife is retracted along with the endoscope as the TCL is transected. The release of the ligament is verified by inserting the 10-mm end of the channeler. The incision is closed with 5-0 nylon sutures. 


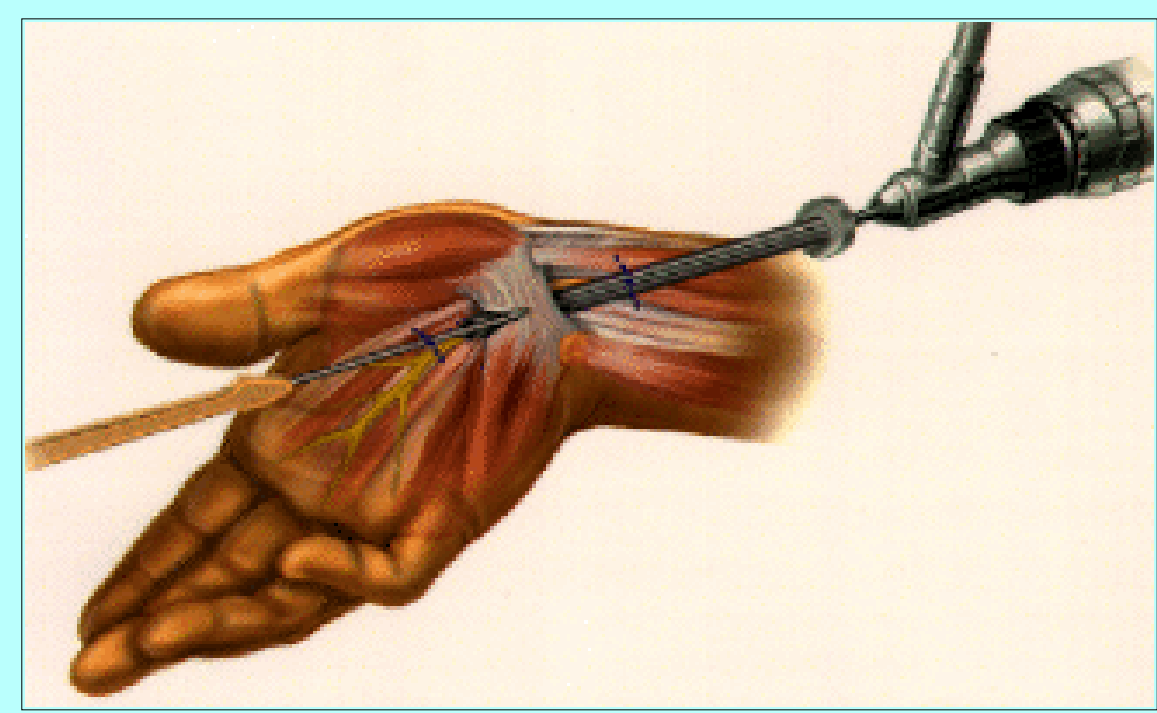

Fig. 4. Artist's illustration showing Chow's biportal technique. A proximal incision is made in the distal forearm. A second incision is made in the palm, immediately distal to the edge of the TCL. A cannula is inserted under the TCL. The hand is held in hyperextension as the endoscope is passed proximal to distal. Several knives are used to cut the TCL in sequential order.

\section{DUAL-PORTAL TECHNIQUES}

\section{Chow Endoscopic Technique}

In 1989, James Chow,[16] an orthopedist at the Southern Illinois School of Medicine, first reported the use of two incisions to dissect the TCL endoscopically (Fig. 4). He worked in conjunction with Smith and Nephew Dyonics, Inc. (Andover, MA) to develop the necessary instrumentation, which includes a slotted cannula and obturator, synovial elevator, probes, and a series of knives (probe, triangle, and retrograde). His original technique involved a transbursal approach to the carpal tunnel. The setup requires the surgeon and assistant to sit across from each other at the hand table. A TV monitor is placed behind each surgeon so that both can have full view of the procedure. A 1-cm transverse incision is made $0.25 \mathrm{~cm}$ proximal and $0.25 \mathrm{~cm}$ radial to the pisiform bone. Chow later modified his technique by changing the landmarks of the proximal incision.[13-15] He recommended that the proximal portal be made by drawing a line 1 to $1.5 \mathrm{~cm}$ radial to the proximal pole of the pisiform bone. A second line is marked $0.5 \mathrm{~cm}$ proximally from the end of the first line. A third line is drawn approximately $1 \mathrm{~cm}$ radial from the end of the second line to indicate the entry portal. A longitudinal incision is made on the antebrachial fascia taking care to protect the ulnar artery and nerve. The flexor tendons are exposed (transbursally) and retracted toward the radial side, finding the space between the ulnar neurovascular bundle and the flexor tendons. A trocar is inserted and the wrist is hyperextended and held in place by a special hand frame. Using the tip of the trocar, the base of the hook of the hamate is felt and then lifted upward and advanced into the palm. A second incision is made $1 \mathrm{~cm}$ proximal to a line that bisects the angle formed by the distal border of the fully abducted thumb and the third web space. The endoscope is inserted proximally into the trocar, which has a slotted end that sits immediately beneath the TCL. Care is taken to make sure that only the transversely running fibers of the TCL are in view and not tendons or nerves. A sequence of cuts is used to transect the ligament. The endoscope is inserted into the proximal end of the slotted cannula and advanced to the distal end of the TCL. A probe (forward-facing) knife is used to cut the distal end in a proximal direction. As the endoscope is moved within the carpal tunnel, a triangle knife is inserted distally and used to make an incision through the midsection of the ligament. A 
retrograde (hook) knife is inserted at the midsection cut and drawn distally to join the first cut, thereby releasing the distal half of the ligament. To finish releasing the TCL, the endoscope is inserted in the distal opening. The probe knife is used to cut the proximal end of the TCL and the retrograde knife is inserted at the midsection and drawn proximally to complete the release. The wounds are sutured, a simple dressing is applied, and the sutures are removed 1 week postsurgery. Because the transbursal technique frequently produced ulnar nerve neuropraxia from either retraction or cannula pressure, the technique was modified by Resnick and Miller[62] to a subligamentous or extrabursal approach. In this technique the antebrachial fascia is incised proximal to the TCL and dissection is performed under the fascia and into the carpal tunnel under the ligament, avoiding the flexor tendon bursa. The rest of the operation is accomplished in a fashion similar to the Chow method.

\section{Brown Biportal Technique}

In 1992, Michael Brown[9] introduced another dual-portal technique for the treatment of CTS. His technique is a modification of Chow's approach, which uses a proximal and distal portal. He worked in conjunction with Instratek, Inc. (Houston, TX) to develop a set of well-designed instruments. Using this approach, the surgeon is positioned so that the dominant hand is closest to the patient. The obturator and blade are held with the dominant hand. The assistant sits at the end of the table and a single TV monitor is placed directly across from the surgeon. The patient's hand is placed in several rolled towels and gently extended. The proximal incision $(1 \mathrm{~cm})$ is made immediately ulnar to the palmaris longus tendon anywhere between 1 and $2 \mathrm{~cm}$ proximal to the distal wrist crease. The median nerve enters the carpal tunnel immediately radial to the palmaris longus; thus, the proximal incision is located away from the nerve. The distal incision is made within a $1-\mathrm{cm}$ circle with an epicenter $4 \mathrm{~cm}$ distal to the distal wrist crease, in line with the third web space. In the majority of patients, the distal end of the TCL will be located $3.25 \pm 0.25 \mathrm{~cm}$ distal to the distal wrist crease. Therefore, the exit portal is typically within 0.5 $\mathrm{cm}$ of the ligament's end. Following extremity exsanguination, the proximal incision is marked and made. The antebrachial fascia is exposed and bluntly spread with the tips of tenotomy scissors. The underlying tendons may be visualized at this point. The synovial elevator is inserted under the fascia and advanced distally. This move places the elevator immediately under the TCL, because the antebrachial fascia blends directly with the TCL. A typical "washboard" sensation is felt as the elevator is moved back and forth, gently removing the synovium. As the elevator is advanced, the edge of the TCL can be easily palpated. The elevator is removed and the obturator is inserted in the same space. Care is taken to assure that the obturator is radial to the hook of the hamate. The tip of the obturator is advanced distally past the distal edge of the TCL. The surgeon's nondominant thumb is used to push dorsally on the palm as the obturator is pressed distally with the dominant hand. This maneuver pushes the palmar arch away from the obturator's tip and assures that only the dermis is present between the tip and the scalpel. A stab incision is made over the obturator's tip and then it is advanced out of the carpal tunnel into the palm. The obturator is removed leaving the slotted cannula in place. The assistant places a 30š angle 4-mm rigid arthroscope through the distal end of the cannula and advances it proximally, visualizing the fibers of the TCL (Fig. 5). The surgeon inserts a hook knife in the proximal port and advances it distally immediately past the end of the TCL. The distal end of the TCL is hooked with a knife and with a steady, continuous pull, the entire ligament is usually transected in a single pass. If necessary, a second or third pass may be performed to transect the ligament fully. Commonly, the fat pad falls into the endoscope's view indicating complete transection. The cannula is removed and, under direct visualization, a proximal volar fasciotomy is performed using tenotomy scissors. Three 5-0 nylon sutures are used to close both wounds. A volar splint (30š extension) is left in place and removed 1 week postsurgery along with the 


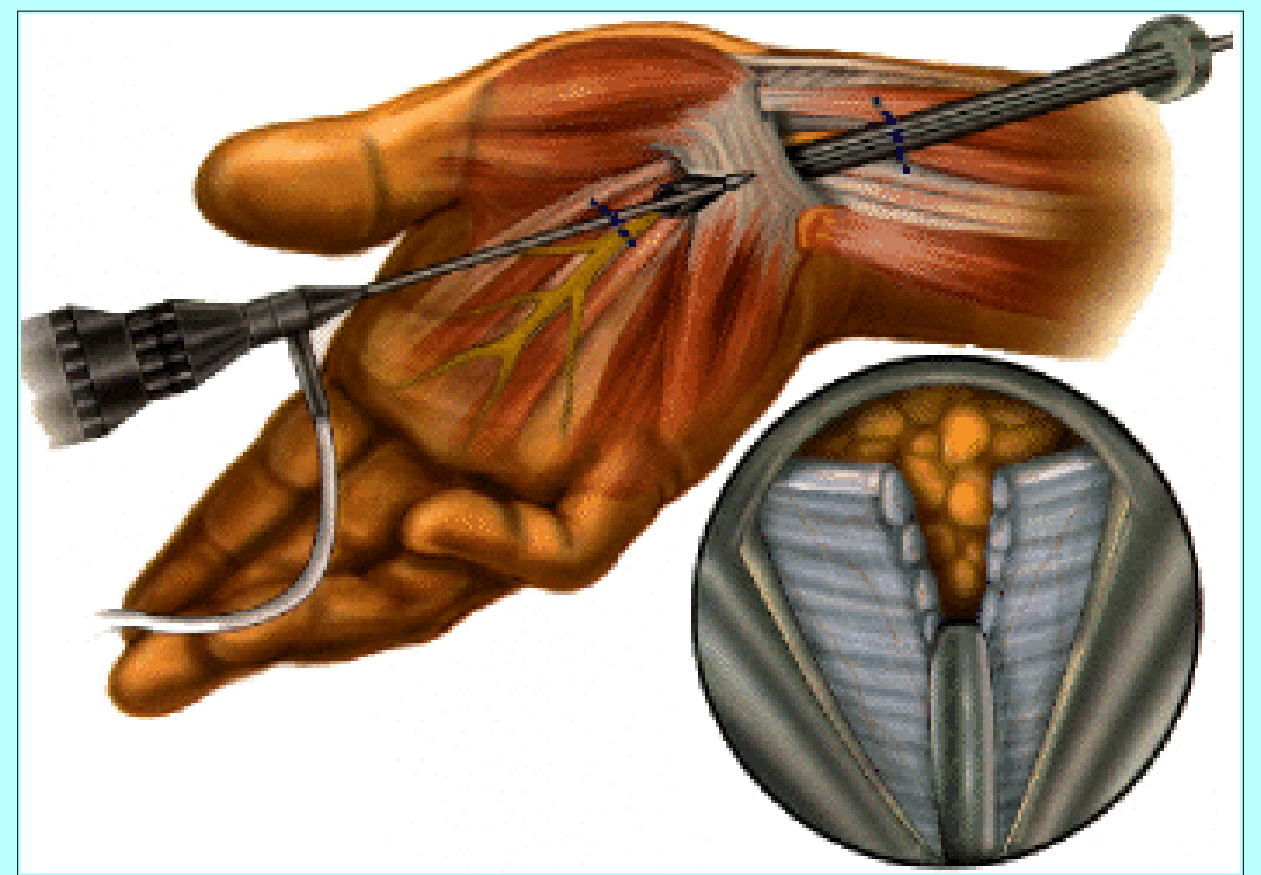

Fig. 5. Artist's illustration showing Brown's biportal technique. Incisions are located similarly to those in Chow's method. A slotted cannula is inserted in the carpal tunnel under the TCL. The surgeon's dominant hand is used to cut the ligament (see insert) distally to proximally. Following transection, the cut edges of the TCL are clearly seen and inspected.

\section{CLINICAL MATERIALS AND METHODS}

A 10-year (1987-1997) literature review was undertaken to identify manuscripts written on the subject of endoscopic release of the TCL for the management of patients with CTS. A total of 52 works were identified and analyzed. The variables tabulated included: type of procedure (single- vs. dual-portal technique), type of study, success rate, failure rate, complications, complications rate, recurrence rate, functional recovery rate, return to work times (patients receiving and not receiving Workers' Compensation), follow-up time, number of procedures, number of patients, and patients' age. Because of the extreme variability of methodology and reporting of these data, a formal analysis could not be adequately performed. The authors of these papers use different definitions of "success," "complications," and "functional recovery." Because the success rates are given in proportions and are all based on different numbers of observations, the weighted average, rather than the simple average of the rates was used. 
TABLE 1

SUMMARY OF RE PORTED CASES ACCORD NG TO TV PE OF ENDOSCOPK TECHN QUE PERFORMED

\begin{tabular}{|c|c|c|c|c|c|c|}
\hline Method & $\begin{array}{l}\text { No. of } \\
\text { Patierts }\end{array}$ & $\begin{array}{c}\text { No. of } \\
\text { Procedures }\end{array}$ & $\begin{array}{l}\text { Avg. Patient } \\
\text { Age (yts) }\end{array}$ & $\begin{array}{l}\text { Success } \\
\text { Rate }[\%]\end{array}$ & $\begin{array}{c}\text { Complication } \\
\text { Rate }[\%]\end{array}$ & $\begin{array}{c}\text { Failure } \\
\text { Rate (\%) }\end{array}$ \\
\hline $\begin{array}{l}\text { Agee } \\
\text { Brown } \\
\text { Chow } \\
\text { Menon } \\
\text { Okutsu } \\
\text { Morseg } \\
\text { total }\end{array}$ & $\begin{array}{r}1,463 \\
1,464 \\
3,505 \\
87 \\
508 \\
64 \\
7,091\end{array}$ & $\begin{array}{r}1570 \\
1472 \\
4112 \\
100 \\
750 \\
64 \\
8068\end{array}$ & $\begin{array}{l}47.2 \\
57 \\
46.05 \\
48.3 \\
54.07 \\
58 \\
51.77\end{array}$ & $\begin{array}{l}96.2 \\
96.01 \\
98.3 \\
94 \\
99.63 \\
95 \\
96.52\end{array}$ & $\begin{array}{l}1.83 \\
1.41 \\
1.87 \\
9 \\
0.4 \\
1.56 \\
2.67\end{array}$ & $\begin{array}{l}1.44 \\
1.78 \\
1.44 \\
0.6 \\
0.3 \\
4.7 \\
2.61\end{array}$ \\
\hline
\end{tabular}

\section{RESULTS}

A total of 8068 endoscopic CTR (ECTR) procedures have been reported (Table 1). These reports were classified according to the technique used and the type of study conducted (Table 2).

\begin{tabular}{|c|c|c|c|c|c|}
\hline Authors \& Year & Type of Study & Technique & $\begin{array}{l}\text { No. of } \\
\text { Patients }\end{array}$ & $\begin{array}{c}\text { No. of } \\
\text { Procedures }\end{array}$ & $\begin{array}{l}\text { Wean } \mathrm{Pa}- \\
\text { tiert Age }\end{array}$ \\
\hline Ágee, et al., 1992 & prospective & Agee & 82 & 82 & - \\
\hline Agee, et al., 1994 & prospectie & Agee & 988 & 1049 & - \\
\hline Arner, et al. 1993 & retrospective & Chow & 48 & 53 & - \\
\hline Bande, et al., 1994 & retrospective & Agee & 44 & 44 & 52 \\
\hline Erown, et al., 1991 & prospectie & Agee & 149 & 149 & - \\
\hline Erown, et al., 1991 & - & Erown & 152 & 152 & - \\
\hline Erown, et al., 1993 & prospective randomized & Brown & 1236 & 1236 & - \\
\hline Erown, et al., 1993 & prospective randomized & Brown & 76 & 84 & 57 \\
\hline Chow, 1990 & review & Chow & 109 & 149 & 49 \\
\hline Chow, 1993 & retrospective & Chow & 456 & 650 & - \\
\hline Elmaraghy \& Hurst, 1996 & prospectie & Agee & 69 & 86 & 51 \\
\hline Erdmann, 1994 & prospecti ve & Chow & 20 & 20 & 56 \\
\hline Erdmann, 1994 & prospective randomized & Chow & 53 & 53 & 53 \\
\hline Feinstein, 1992 & retrospective & Agee & 55 & 61 & 45 \\
\hline Friol, et al., 1994 & retrospective & Chow & 1400 & 1400 & 49 \\
\hline Futami, 1995 & retrospective & Chow & 10 & 10 & 53 \\
\hline Hallock \& Lut, 1994 & prospectie & Chow & 47 & 66 & 47 \\
\hline Jacotsen \& Rahme, 1996 & prospective randomized & Chow & 29 & 32 & 44 \\
\hline Kelly, et al., 1994 & prospective & Chow & 69 & 97 & 50 \\
\hline Kerr, et al., 1994 & review & Chow & 75 & 100 & 44.8 \\
\hline Lenick y 1994 & retrospective & Chow & 50 & 71 & 47.5 \\
\hline McDonough \& Gruenloh, 1993 & retrospective & Chow & 34 & 45 & 45.4 \\
\hline McDonough \& Gruenloh, 1993 & retrospective & Agee & 5 & 5 & 45.4 \\
\hline Menon, 1994 & retrospective & Menon & 87 & 100 & 48.3 \\
\hline Nagle, et al., 1996 & prospective & Chow & - & 110 & 48 \\
\hline Nagle, et al., 1996 & prospective & Chow & - & 530 & 48 \\
\hline Okutsu, et al., 1993 & retrospective & Okutsu & 138 & 199 & 52.9 \\
\hline Okutsu, et al., 1993 & retrospective & Okutsu & 370 & 551 & 54.5 \\
\hline Palmer, et al., 1993 & prospectie & Aggee & 70 & 90 & 44.9 \\
\hline Palmer, et al., 1993 & prospective & Chow & 62 & 72 & 46.8 \\
\hline Resnick \& Miller, 1991 & retrospective & Chow & $6 \overline{5}$ & 75 & - \\
\hline Roth, et al ., 1994 & prospective & Chow & 95 & 108 & 52.4 \\
\hline Skoff \& Sklar, 1993 & retrospective & Chow & 20 & 20 & 57 \\
\hline Sattery 1992 & retrospective & Chow & 215 & 215 & 41 \\
\hline Viegas, et al., 1992 & retrospective & Chow & 102 & 108 & 48 \\
\hline humees at al taoe & momanomitis & Hhoves a & EA & EA & E \\
\hline
\end{tabular}


The success rate varied between $78 \%$ and $100 \%$ (Table 3), although the definition of success was not uniform from paper to paper. All reported complications are presented in Table 4.

\begin{tabular}{|c|c|c|c|c|c|}
\hline Authors \& Year & $\begin{array}{c}\text { Follow } \\
\text { Up [ } w k s]\end{array}$ & $\begin{array}{l}\text { Success } \\
\text { Rate }(\%)\end{array}$ & How Defined & $\begin{array}{l}\text { Com- } \\
\text { plicalion } \\
\text { Rate }(\%)\end{array}$ & $\begin{array}{c}\text { Recis- } \\
\text { rence } \\
\text { Rate }[\%]\end{array}$ \\
\hline Agee, et al., 1992 & 26 & 95.1 & relief of symptoms & 2.44 & 0 \\
\hline Agee, et al., 1994 & 3.5 & 95.7 & relief of symptoms & 1.8 & - \\
\hline Arner, et al., 1993 & 52 & 91.4 & return to normal sensation & 28.6 & - \\
\hline Bande, et al., 1994 & 72 & 93.2 & patient satisfaction & $\stackrel{0}{0}$ & 0 \\
\hline $\begin{array}{l}\text { Brown, et al., } 1991 \\
\text { Brown, et al. } 1991\end{array}$ & $\begin{array}{l}40 \\
40\end{array}$ & $\begin{array}{l}97.4 \\
100\end{array}$ & $\begin{array}{l}\text { relief of sym ptoms } \\
\text { relief of sym ptoms }\end{array}$ & 6 & $\begin{array}{l}1.3 \\
0\end{array}$ \\
\hline Erown, et al., 1993 & 120 & 96 & return to $\mathrm{ADL}$ & 0.97 & $\frac{0}{2}$ \\
\hline Erown, et al., 1993 & 12 & 89 & patient satisfaction & - & - \\
\hline Chow, 1990 & 62 & 99 & relief of sym ptoms & 0.67 & 0 \\
\hline Chow, 1993 & 116 & 98 & return to $\mathrm{ADL}$ & 0 & 0.15 \\
\hline Elmaraghy \& Hurst, 1996 & 10 & 90 & relief of sym ptoms & 8 & 0 \\
\hline $\begin{array}{l}\text { Erdmann, } 1994 \\
\text { Erdmann, } 1994\end{array}$ & $\begin{array}{l}52 \\
52\end{array}$ & $\begin{array}{l}80 \\
98.1\end{array}$ & $\begin{array}{l}\text { relief of sym ptoms } \\
\text { relief of sum otoms }\end{array}$ & $\begin{array}{l}15 \\
1.9\end{array}$ & $\begin{array}{l}10 \\
1.9\end{array}$ \\
\hline Feinstein, 1992 & 52 & 98.4 & patient satisfaction & - & - \\
\hline Friol, et al., 1994 & 24 & 99.4 & return to $\mathrm{ADL}$ & 0.43 & 0.07 \\
\hline Futami, 1995 & 135 & 100 & patient satisfaction & - & - \\
\hline Hallock \& Lut, 1994 & - & 92 & relief of sym ptoms & 48.4 & 0 \\
\hline Jacobsen \& Rahme, 1996 & 24 & 100 & relief of symptoms & 10.3 & 0 \\
\hline Kelly, et al., 1994 & 28 & 78 & patient satisfaction & 12.4 & 5.2 \\
\hline Kerr, et al., 1994 & - & 100 & relief of symptoms & 33 & 0 \\
\hline Lewick y 1994 & 36 & 98.6 & relief of sym ptoms & 1.4 & 0 \\
\hline McDonough \& Gruenloh, 1993 & 14 & 98.8 & relief of sym ptoms & 2.2 & 2.2 \\
\hline Menon, 1994 & 106 & 94 & relief of sym ptoms & 9 & 6 \\
\hline Nagle, et al., 1996 & 52 & 85 & relief of sym ptoms & 11 & 7.3 \\
\hline Nagle, et al., 1996 & 52 & 97.4 & relief of sym ptoms & 2 & 1.3 \\
\hline Okutsu, et al., 1993 & 73.2 & 100 & return to normal sensation & 0 & 0 \\
\hline Okutsu, et al., 1993 & 67.6 & 99.5 & relief of sym ptoms & 0.54 & 0.54 \\
\hline Palmer, et al., 1993 & 24 & 88 & relief of symptoms & 10 & 2.2 \\
\hline Palmer, et al., 1993 & 24 & - & relief of sym ptoms & 13 & 4.1 \\
\hline Palmer, et al., 1993 & 24 & 97 & relief of sym ptoms & 10 & 0 \\
\hline Palmer, et al., 1993 & 24 & 95 & relief of symptoms & 13 & 0 \\
\hline Resnick \& Miller, 1991 & - & 92 & relief of sym ptoms & 8 & - \\
\hline Roth, et al., 1994 & - & 98 & relief of sym ptoms & 3.8 & - \\
\hline Skoff \& Sklar, 1993 & 52 & 100 & patient satisfaction & & 0 \\
\hline Sattery 1992 & - & 96 & relief of symptoms & 3.26 & 0 \\
\hline Viegas, et al., 1992 & - & 99 & pinch and grip strength & & - \\
\hline Worseg, et al., 1996 & 24 & 95 & return to $\mathrm{ADL}$ & 1.56 & 0 \\
\hline
\end{tabular}


TABLE 4

COMPL CATIONS ASSOC ATED WITH ECTR OF THE TCL

\begin{tabular}{|c|c|}
\hline Authors \& Year & Complications \\
\hline Ágee, et al., 1992 & transient ulnar neuro praxia \\
\hline Agee, et al., 1994 & $\begin{array}{l}\text { abnormal sensation, sensory loss in palm, infection, incision pain, reflex } \\
\text { sym pathetic dystrophy, ulnar ner we hyperesthe sia. }\end{array}$ \\
\hline Arner, et al., 1993 & sensory disturbances \\
\hline Bande, et al., 1994 & none \\
\hline Erown, et al., 1991 & reflex sym pathetic dystrophy \\
\hline Erown, et al., 1991 & reflex sym pathetic dystroph y transient paresthesias \\
\hline Erown, et al., 1993 & ia trogenic injury, reflex sym pathetic dystrophy, transient paresthesias \\
\hline Erown, et al., 1993 & $\begin{array}{l}\text { injury to superficial palmar arch, numbness, ulnar ner 'e paresthe sias, } \\
\text { mound hematoma. }\end{array}$ \\
\hline Chow, 1990 & ulnar ner'e paresis \\
\hline Chow, 1993 & transient ulnar nerve palsy \\
\hline Elmaraghy \& Hurst, 1996 & pillar pain, weak grip, paresthesia \\
\hline Erdmann, 1994 & ulnar ner ve neuropraxa \\
\hline Erdmann, 1994 & ulnar ner'e neuropraxia \\
\hline Feinstein, 1992 & pillar pain, scar tenderness, pinch g̣ip meakness, persistent num tness \\
\hline Friol, et al., 1994 & $\begin{array}{l}\text { sympathetic dysunction, partial lesion of superficial palmar arch, interdig- } \\
\text { ital nerve lesion }\end{array}$ \\
\hline Futami, 1995 & ( \\
\hline Hallock \& Lut, 1994 & painful scar, pillar pain, infection \\
\hline Jacotsen \& Rahme, 1996 & transie \\
\hline Kelly, et al., 1994 & incomplete division, ner'e damage \\
\hline Kerr, et al., 1994 & incision tendemess \\
\hline Lewick y 1994 & reflex sym pathetic dystrophy \\
\hline Luallin, 1993 & Guyon's canal rele ase \& scarring \\
\hline $\begin{array}{l}\text { McDonough \& Gruenloh, } \\
1993\end{array}$ & flewor digitorum sublim is laceration \\
\hline Menon, 1994 & pillar pain, neuropraxa, ulnar ner we comm \\
\hline Nagle, et al., 1996 & median nerve transection, superficial palma \\
\hline Nagle, et al., 1996 & $\begin{array}{l}\text { neuropraxia of median, ulnar, \& common digital ner wes, laceration flewor } \\
\text { digitorum sutlimis } 4 \& 5\end{array}$ \\
\hline Okutsu, et al., 1993 & $\begin{array}{l}\text { neuropraxia of median, ulnar, \& common digital ner 'es, laceration of } \\
\text { superior palmar arch }\end{array}$ \\
\hline Okutsu, e & ulnar ner we transection \\
\hline al., 1993 & suboutaneous hematoma \\
\hline Palmer, et al., 1993 & ulnar ner've paresthesia. \\
\hline Palmer, et al., 1993 & ulnar ner'e paresthe sia \\
\hline Palmer, et al. 1993 & ulnar ner'e paresthesia. \\
\hline Resnick \& Miller, 1991 & ulnar ner'e paresthesia \\
\hline $\begin{array}{l}\text { Roth, et al., } 1994 \\
\text { Skoff \& Sklar, } 1993\end{array}$ & $\begin{array}{l}\text { wound hematom a, superficial cellulitis, in flammatory flewor tenosynowits } \\
\text { paresthesia. }\end{array}$ \\
\hline Sattery 1992 & $\begin{array}{l}\text { neuropraxia of ulnar ner ie, reduced sensation, reflex sym pathetic dystro- } \\
\text { phy }\end{array}$ \\
\hline Viegas, et al., 1992 & transient neuroprasia \\
\hline Morseg. & t neuropraxia of third common digital nerve \\
\hline
\end{tabular}

Return to work times averaged 21.75 days, ranging between 4 days and 39.8 days (Table 5). Patients not receiving Workers' Compensation had a mean return to work time of 17.8 days, ranging between 10.8 days and 22.3 days. 


\begin{tabular}{|lccccc|}
\hline \multicolumn{5}{c}{ TABLE 5 } \\
AVERAGE NUMBER OF DAVS BEFORE RE TURN TO WORK FOR PATIENTS \\
RECEIV NG AND NOT RECEIV NG WORKERS' COMPENSAT ON \\
STRAT ED BV PROCEDURE TV PE
\end{tabular}

Nine articles have been published describing results obtained using Agee's monoportal technique in a total of 1463 patients undergoing 1570 procedures.[2-4,6,11,19,22,39,54] The combined success rate reported in these articles was $96.2 \%$, with a complication rate of $1.83 \%$ and a failure rate of $1.44 \%$. The complications associated with this technique include reflex sympathetic dystrophy, ulnar neuropraxias, palmar sensory loss, infection, pillar pain, weak grip, scar tenderness, flexor digitorum sublimis laceration, and hematoma. Three articles were published describing results obtained using the original single-portal Okutsu technique in a total of 508 patients undergoing 750 procedures.[46,48,49] Okutsu reported a success rate of $99.63 \%$, with a complication rate of $0.4 \%$ and a failure rate of $0.3 \%$. The only reported complication was a subcutaneous hematoma. The articles published by Menon[40,41] on his technique reported a total of 87 patients undergoing 100 procedures. He reported a success rate of $94 \%$ and the highest complication rate of all articles at $9 \%$ and a recurrence rate of $0.6 \%$. Complications reported included pillar pain, neuropraxia, and ulnar nerve communicating branch injury. Only one article[74] dealt with Worseg's technique and it was included for completeness. He reported on 64 procedures in 64 patients. The success rate was $95 \%$, with a complication rate of $1.56 \%$ and the highest failure rate of 4.7. Complications reported included postoperative pain and transient neuropraxia of the third common digital nerve.

The most widely performed and reported procedure was Chow's dual-portal technique. There were 20 articles describing 3505 patients undergoing 4112 procedures.[5,13-16,20,23,25,28,30,32,36,39,43,54,62,64,70-72] The average success rate reported in these publications was $98.3 \%$, with a complication rate of $1.87 \%$ and a failure rate of $1.44 \%$. 
Complications included ulnar nerve neuropraxia and paresthesias, which were most common when ulnar nerve retraction was used during the earlier transbursal method. The incidence of ulnar nerve neuropraxia decreased with the advent of the extrabursal method. Other complications included reflex sympathetic dystrophy, superficial palmar arch injury, interdigitial lesion, Guyon's canal release, and scarring.[37] A total of 1464 patients underwent surgery via Brown's dual-portal technique.[9,10] A total of 1472 procedures were performed with a reported success rate of $96 \%$, a complication rate of $1.41 \%$, and a failure rate of $1.78 \%$. Transient paresthesias, reflex sympathetic dystrophy, and injury to the superficial palmar arch were reported complications with this procedure. Five papers dealt strictly with complications of endoscopic techniques.[17,18,42,44,68] Complications reported included transection of the motor branch of the ulnar nerve, laceration of the ulnar nerve at Guyon's canal, pseudoaneurysm of the superficial palmar arch, median nerve transection, and laceration of the flexor digitorum superficialis four and five.

\section{DISCUSSION}

Carpal tunnel syndrome is currently the most common peripheral nerve compression neuropathy affecting an estimated $1 \%$ of the population. $[21,50,55]$ The incidence of CTS appears to be increasing in the workplace. Diagnosis is based on clinical symptoms and corroborated with electrodiagnostic studies. Since Phalen[58-60] introduced and popularized carpal tunnel decompression in the 1950s, open transection of the TCL has become the gold standard in the surgical treatment of this condition. Nevertheless, several disadvantages have been associated with open CTR (OCTR) including pillar pain, hand weakness, scar tenderness, delay in returning to work, and slower recovery of function. In recent years, there has been a major interest in minimally invasive surgery. The use of endoscopes is now commonplace in many specialties including neurosurgery. Following the introduction of the endoscope by Okutsu in 1987,[47] significant interest flourished in those specialties caring for patients with CTS, mainly orthopedics and plastic surgery.[1,7,29,33-35,63,65,67,69] Major controversy has ensued between camps (open vs. endoscopic) and within camps (open vs. open; endoscopic vs. endoscopic) regarding the safety, success, and most important, the complication rates of the two procedures. Difficulties in discerning which procedure is best arise from the lack of consensus as to which is the best open technique. Analysis of the OCTR literature reveals remarkable variability regarding the location, length, and shape of the incision. The incision can be located proximal to midpalm,[26; $p$ 107] across the distal wrist crease and into the forearm,[26; pp 105-106, 108] along the axis of the third web space,[27; pp 111-114] third digit,[27; pp 112-113] fourth digit,[27; pp 109-110] or along the thenar crease.[26; pp 108-109] The shape of the incision may be curved,[26; pp 107-109] straight,[26; 108-110] sigmoid,[27; pp 110-111] or a combination thereof.[26; pp 106-108] The size of the incision may vary between $2 \mathrm{~cm}$ and $8 \mathrm{~cm}$.[26; pp 105-106] There is significant enough variation among the aforementioned approaches to classify them as different procedures. Thus, an across the board comparison between techniques is quite difficult. Nonetheless, the consensus is that the success rate of OCTR surgery is greater than 95\%, with a complication rate of less than $3 \%$.

Interest in less invasive open procedures for treating CTS developed in the early 1980s. Paine,[52] a neurosurgeon, used a retinaculatome to divide the TCL through a small transverse incision in one of the wrist creases. However, he discovered a $2.5 \%$ incidence of incomplete division of the TCL at reoperation. There were four cases of palmar hematoma that most likely developed due to injury to the superficial palmar arch. Pagnanelli[53] reported the use of the retinaculatome in 577 patients and only had two incomplete divisions $(0.3 \%)$ of the TCL with no median nerve or vascular injuries. 
This review indicates that the success, complication, and failure rates of the ECTR are comparable to those of OCTR procedures. However, as with OCTR techniques, there is significant variability in ECTR procedures. To date, seven papers have been written that directly compare ECTR and OCTR techniques for the treatment of CTS. The total number of patients included in these studies was 505, with 642 procedures performed. Only one study[28] was prospective, blinded, and randomized. In that study, 29 patients underwent 32 procedures. One-half of the procedures were randomized either to Chow's (transbursal) method or to an open technique. The variable analyzed was the time to return to work. Statistically, no significant difference was found between the ECTR (mean 17 days) and OCTR (mean 19 days) techniques. Hallock and Lutz[25] studied 96 patients prospectively, in nonrandomized fashion, and specifically compared ECTR (Chow's extrabursal technique) with a minimally invasive open technique (2-cm palmar incision), given the extreme variability and the types of open techniques performed. Seventy-one hands were treated using the OCTR technique and 61 hands using the ECTR method. No statistically significant differences were found between the two techniques regarding return to work, scar length, or complication rates. Skoff[70] compared 20 patients who underwent surgery via the Chow transbursal method with 20 patients in whom open sectioning of the TCL was performed. That study also found no significant differences in either group with respect to postoperative grip strength, two-point discrimination, and sensation. Kerr[31] compared 100 dual-portal ECTR procedures, performed using the Chow technique, with a retrospectively matched group of patients who underwent standard OCTR techniques. He found no difference in complication rates between the two procedures. When comparing return to work time, patients who underwent ECTR surgery and were not receiving Workers' Compensation returned to work an average of 15.6 days sooner than those who underwent OCTR. He also found that all patients receiving Workers' Compensation took significantly longer to return to work. In a single-center prospective nonrandomized study[54] Agee's (90 patients), Chow's (72 patients), and open (49 patients) procedures were compared. Patients who underwent ECTR achieved faster recovery of grip and pinch strength, wrist range of motion and less palmar tenderness (Agee's group had the least); patients with OCTR reported more weakness and pain with activities of daily living after surgery. The patients who underwent ECTR procedures returned to work sooner than those in whom an OCTR was performed (Agee: mean 12.8 days; Chow: mean 16.9 days; and open: mean 37.3 days). No difference was found in sensory or motor testing in the pre- and postoperative period between treatment groups. Futami[24] reported on 10 patients who had bilateral CTS and who underwent OCTR in one hand and ECTR surgery in the other hand. No postoperative differences were found in resolution of symptoms or in postoperative grip strength between the groups. The time to return to activities of daily living was a mean of 12 days for those patients who underwent ECTR versus 41 days for patients who underwent an OCTR procedure. The patients preferred ECTR because of smaller incisions, less postoperative pain, and earlier use of the hand. A retrospective study by Bande, et al.,[6] compared two similar groups of patients who underwent either ECTR (Agee's single-portal technique, 44 patients) or open decompression (58 patients). No significant difference in relief of symptoms or return to work time was found between these two groups. Patient satisfaction at 6- and 18-month follow-up times was high in both techniques.

Schenck[66] reported on the results of a retrospective questionnaire that was sent to 1532 surgeons in 1992. There was a response rate of 832 (54\%). The survey categorized the methods into the Agee, Chow, and other. The ECTR technique was used in 185 surgical series by 157 surgeons for a total of 6833 procedures. Their overall reported complication rate was $2.6 \%$. Of the total number of operations, $2.7 \%$ had to be converted to an open procedure because of technical difficulties. The complication rate for the Agee method was $2 \%$ and the complication rate for the Chow method was $3.1 \%(\mathrm{p}=0.02219)$. The ECTR rate for nerve, artery, and tendon complication was 1.6\%, compared with an OCTR rate of $0.8 \%$ 
$(\mathrm{p}=0.00481)$. However, in many of these complication rates, transient paresthesias were counted and later excluded, thus losing the significance. Recurrent or persistent symptoms were nearly identical between the ECTR (7.5\%) and the OCTR procedures (7.7\%).

\section{CONCLUSIONS}

The results of this review show reported success, complication, and failure rates for ECTR surgery are acceptable and comparable to those of OCTR procedures in properly selected patients. Furthermore, many patients undergoing ECTR were reported to return to work and activities of daily living sooner than patients undergoing OCTR operations. In addition, patients reported less pain and tenderness during the postoperative period. Nevertheless, several important issues must be discussed.

Patient Selection. Appropriate patient selection is extremely important for a successful outcome. Only patients with classic CTS should be considered candidates. Contraindications include patients with known anatomical anomalies, ganglion or synovial cysts, neuromas, history of fractures, inflammatory or septic tenosynovitis, previously unsuccessful CTR, and others. Very large, bulky hands are sometimes technically difficulty to operate on.

Surgical Training. Undoubtedly there is a steep learning curve associated with some of these procedures. Surgeons unfamiliar with endoscopes, instruments, and endoscopic techniques, may find these procedures technically demanding. Proper formal training in these techniques must be obtained. The surgeon should become thoroughly familiar with endoscopic anatomy and anatomical relationships within the carpal tunnel. The many guidelines available should be strictly followed and understood. It is strongly recommended that following formal training, the surgeon repeatedly perform the procedure in cadaver specimens (with the instruments and technique of choice) until a sense of comfort, understanding, and consistency are obtained.

Procedure Conversion. If, despite properly following technical guidelines, anatomical anomalies are encountered or adequate visualization and identification of anatomical landmarks is not possible, the surgeon should be prepared to abort the ECTR approach and convert it to an OCTR procedure. Most complications occur when the surgeon tries to perform an ECTR at all costs. The patient should be informed beforehand of the real possibility of conversion to an OCTR operation.

General Considerations. There are several principles that are applicable to any ECTR technique used to transect the TCL. The anesthesia used is the surgeon's choice. Local anesthesia, regional block, Bier block, mask general, or general endotracheal anesthesia have all been used successfully. It is perhaps wise to begin with general mask (propofol only) before attempting to perform the procedure with the patient receiving a local anesthetic. A certain degree of discomfort (and arm movement) is felt by the patient when the obturator is inserted into the carpal tunnel. For this reason, many surgeons (including those at our center) prefer general anesthesia. An intravenous line is placed and a loading dose of propofol $(1 \mu \mathrm{g} / \mathrm{kg})$ is given followed by a maintenance dose $(0.1 \mu \mathrm{g} / \mathrm{kg} / \mathrm{hour})$. The anesthesiologist can use a face mask or a laryngeal airway to oxygenate the patient adequately. Almost immediately after the propofol infusion ceases, the patient wakes up. Nevertheless, these procedures can all be performed safely and rapidly with any type of anesthesia.

Visualization is of paramount importance when performing endoscopic procedures of any kind. Extremity exsanguination using an Esmarch bandage followed by inflation of a tourniquet above systolic pressure allows for a bloodless field. Even the slightest amount of blood can obscure the field and 
disguise the normal appearance of the carpal tunnel structures. Tourniquet time is usually less than 10 minutes. There is no advantage in performing the procedure without the use of a tourniquet.

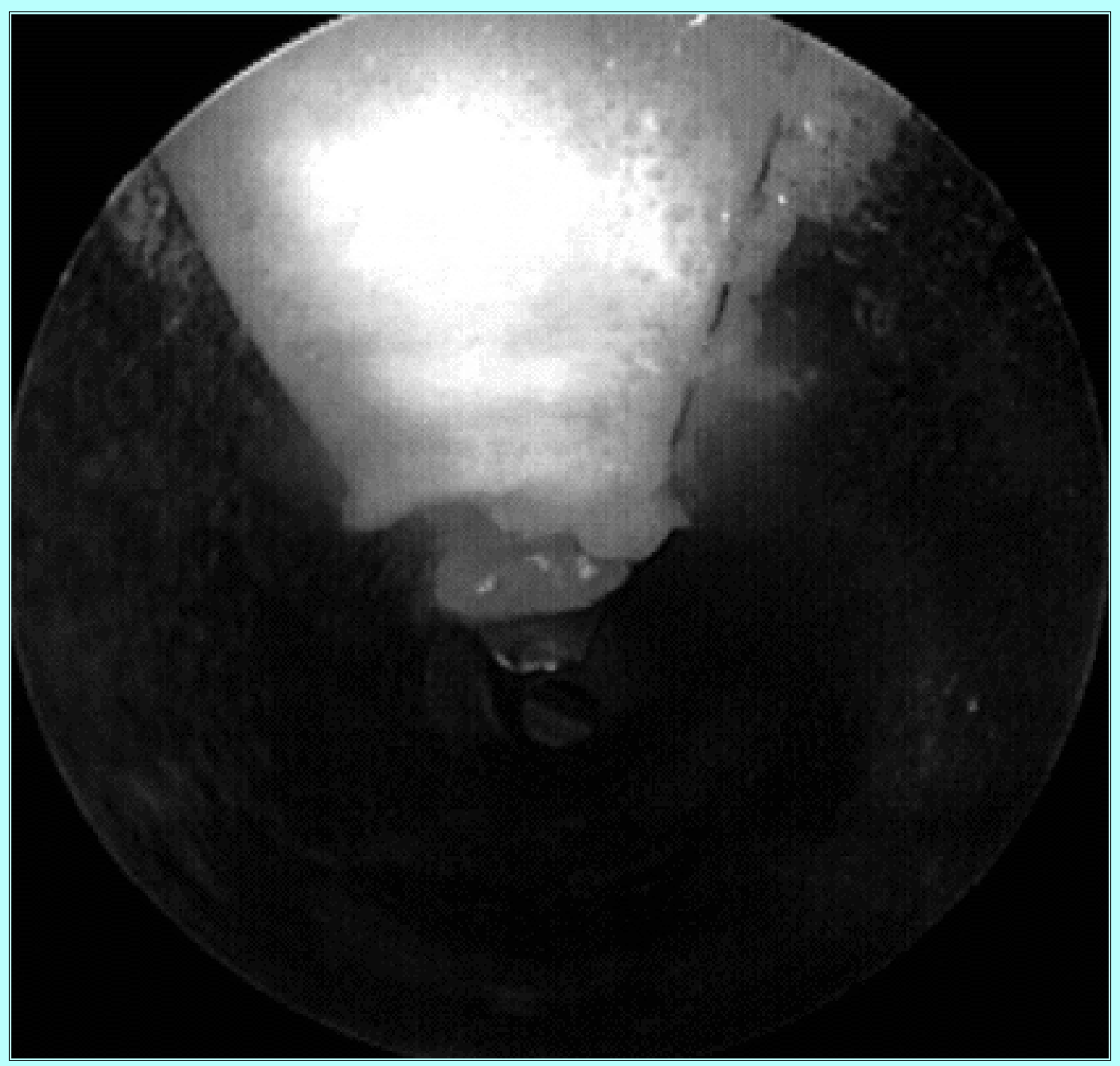

Fig. 6. Intraoperative endoscopic view of the undersurface of the TCL showing the open end of the cannula, which is visualized superiorly along with the white transversely running fibers of the TCL. Tendons and the median nerve are protected and located on the outside of the cannula.

An extremely important principle in the safe transection of the TCL is visualization and identification of the undersurface of the ligament. The fibers of the ligament run transversely in an ulnar to radial direction. Following adequate removal of synovium from its undersurface, the white, glistening transversely running fibers of the TCL should be clearly visualized (Figs. 6 and 7). Care must be taken not to push through the volar forearm fascia and track between the palmar fascia and the TCL. Any fibers seen coursing longitudinally along the axis of the cannula should be moved out of the way because they can only be tendon or neural fibers. 


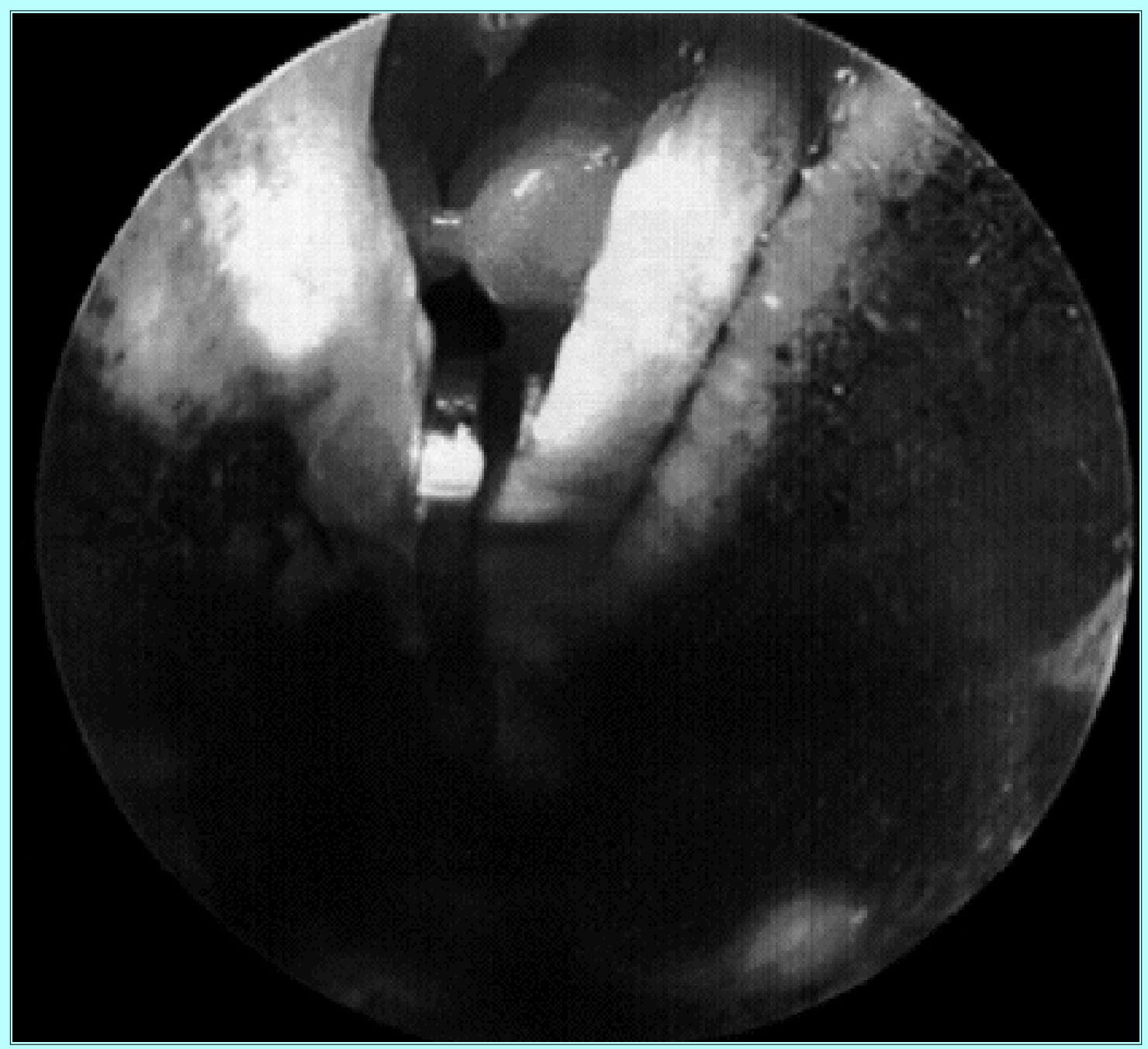

Fig. 7. Intraoperative photograph showing direct endoscopic visualization of the TCL being cut by a hook knife. The cut ends of the TCL are clearly seen. The fat pad, lying above the TCL can also be seen. A completely transected TCL can be easily seen and documented.

Ultimately, which procedure is best, open or endoscopic? The answer lies with the surgeons and the procedure with which they are the safest and most comfortable. There is no need to change from a minimally open technique, if it has provided the surgeon with excellent results. However, neurosurgeons should be aware of and knowledegable about endoscopic procedures. Which endoscopic procedure is best? Again, the surgeon's comfort and proper knowledge of the technique are important. Subligamentous or extrabursal techniques are, however, superior to the transbursal method. Our procedure of choice is the dual-portal technique of Brown. The results we obtained in our first 50 consecutive cases indicate a success rate of $98 \%$, a complication rate of $2 \%$ (one patient) and a reoperation rate of $2 \%$ ( 1 patient). Patient return to work times varied between 2 and 15 days, with a mean of 10 days. Patient satisfication has been extremely high. Four patients who underwent both the open and closed procedures emphatically favored the significantly less painful ECTR technique. Our current approach is to proceed with the dual-portal technique in carefully selected patients with CTS and to perform minimally open $(2-\mathrm{cm})$ procedures in all others. Given the acceptable success and complication rates of ECTR surgery, neurosurgeons should become familiar with the endoscopic management of CTS. 
The authors do not have any financial investment or relationship with the manufacturers of endoscopic carpal tunnel equipment.

\section{Acknowledgments}

The authors wish to thank Mary Bess for her assistance in the preparation of this manuscript. All illustrations are by Craig Bowman, medical illustrator.

\section{References}

1. Adams BD: Endoscopic carpal tunnel release. J Am Acad Orthop Surg 2:179-184, 1994

2. Agee JM, McCarroll HR, North ER: Endoscopic carpal tunnel release using the single proximal incision technique. Hand Clin 10:647-659, 1994

3. Agee JM, McCarroll HR, Tortosa RD, et al: Endoscopic release of the carpal tunnel: a randomized prospective multicenter study. J Hand Surg (Am) 17:987-995, 1992

4. Agee JM, Peimer CA, Pyrek JD, et al: Endoscopic carpal tunnel release: a prospective study of complications and surgical experience. J Hand Surg (Am) 20:165-171, 1995

5. Arner M, Hagberg L, Rosen B: Sensory disturbances after two-portal endoscopic carpal tunnel release: a preliminary report. J Hand Surg (Am) 19:548-551, 1994

6. Bande S, De Smet L, Fabry G: The results of carpal tunnel release: open versus endoscopic technique. J Hand Surg (Br) 19:14-17, 1994

7. Berger RA: Endoscopic carpal tunnel release. A current perspective. Hand Clin 10:625-636, 1994

8. Brain WR, Wright AD, Wilkinson M: Spontaneous compression of both median nerves in the carpal tunnel. Lancet 1:277-282, 1947

9. Brown MG, Keyser B, Rothenberg ES: Endoscopic carpal tunnel release. J Hand Surg (Am) 17:1009-1011, 1992

10. Brown MG, Rothenberg ES, Keyser B, et al: Results of 1236 endoscopic carpal tunnel release procedures using the Brown technique. Contemp Orthop 27:251-258, 1993

11. Brown RA, Gelberman RH, Seiler JG III, et al: Carpal tunnel release. A prospective, randomized assessment of open and endoscopic methods. J Bone Joint Surg (Am) 75:1265-1275, 1993

12. Cannon BW, Love JG: Tardy median palsy; median neuritis; median thenar neuritis amenable to surgery. Surgery 20:210-216, 1946

13. Chow JC: The Chow technique of endoscopic release of the carpal ligament for carpal tunnel syndrome: four years of clinical results. Arthroscopy 9:301-314, 1993

14. Chow JC: Endoscopic carpal tunnel release. Two-portal technique Hand Clin 10:637-646, 1994

15. Chow JC: Endoscopic release of the carpal ligament for carpal tunnel syndrome: 22 -month clinical result. Arthroscopy 6:288-296, 1990 
16. Chow JC: Endoscopic release of the carpal ligament: a new technique for carpal tunnel syndrome. Arthroscopy 5:19-24, 1989

17. Cobb TK, Carmichael SW, Cooney WP: The ulnar neurovascular bundle at the wrist. A technical note on endoscopic carpal tunnel release. J Hand Surg (Br) 19:24-26, 1994

18. De Smet L, Fabry G: Transection of the motor branch of the ulnar nerve as a complication of two-portal endoscopic carpal tunnel release: a case report. J Hand Surg (Am) 20:18-19, 1995

19. Elmaraghy MW, Hurst LN: Single-portal endoscopic carpal tunnel release: Agee carpal tunnel release system. Ann Plast Surg 36:286-291, 1996

20. Erdmann MW: Endoscopic carpal tunnel decompression. J Hand Surg (Br) 19:5-13, 1994

21. Eversmann WW Jr: Entrapment and compression neuropathies, in Green DP (ed): Operative Hand Surgery. New York: Churchill Livingstone, 1993, Vol 2, pp 957-1009

22. Feinstein PA: Endoscopic carpal tunnel release in a community-based series. J Hand Surg (Am) 18:451-454, 1993

23. Friol JP, Chaise F, Gaisne E: [Endoscopic decompression from the median nerve to the carpal canal.] Ann Chir Main Memb Sup 13:162-171, 1994 (Fr)

24. Futami T: Surgery for bilateral carpal tunnel syndrome. Endoscopic and open release compared in 10 patients. Acta Orthop Scand 66:153-155, 1995

25. Hallock GG, Lutz DA: Prospective comparison of minimal incision "open" and two-portal endoscopic carpal tunnel release. Plast Reconstr Surg 96:941-947, 1995

26. Hudson AR, Wissinger JP, Salazar JL, et al: Carpal tunnel syndrome. Surg Neurol 47:105-114, 1997

27. Hunt JR: The thenar and hypothenar types of neural atrophy of the hand. Am J Med Sci

141:224-241, 1911

28. Jacobsen MB, Rahme H: A prospective, randomized study with an independent observer comparing open carpal tunnel release with endoscopic carpal tunnel release. J Hand Surg (Br) 21:202-204, 1996

29. Kato T, Kuroshima N, Okutsu I, et al: [Morphologic analysis of carpal canal with MRI before and after endoscopic release of transverse carpal ligament.] J Jpn Soc Surg Hand 7:464-467, 1990 (Jpn)

30. Kelly CP, Pulisetti D, Jamieson AM: Early experience with endoscopic carpal tunnel release. J Hand Surg (Br) 19:18-21, 1994

31. Kerr CD, Gittins ME, Sybert DR: Endoscopic versus open carpal tunnel release: clinical results. Arthroscopy 10:266-269, 1994

32. Learmonth JR: The principle of decompression in the treatment of certain diseases of peripheral nerves. Surg Clin North Am 13:905-913, 1933

33. Lee DH, Masear VR, Meyer RD, et al: Endoscopic carpal tunnel release: a cadaveric study. J Hand Surg (Am) 17:1003-1008, 1992 
34. Lee H, Jackson TA: Carpal tunnel release through a limited skin incision under direct visualization using a new instrument, the carposcope. Plast Reconstr Surg 98:313-320, 1996

35. Levy HJ, Soifer TB, Kleinbart FA, et al: Endoscopic carpal tunnel release: an anatomic study. Arthroscopy 9:1-4, 1993

36. Lewicky RT: Endoscopic carpal tunnel release: the guide tube technique. Arthroscopy 10:39-49, 1994

37. Luallin SR, Toby EB: Incidental Guyon's canal release during attempted endoscopic carpal tunnel release: an anatomical study and report of two cases. Arthroscopy 9:382-386, 1993

38. Marie P, Foix: Atrophie isolée de l'éminence thénar d'origine névritique; rôle du ligament annulaire antérieur du carpe dans la pathologie de la lésion. Rev Neurol 26:647-649, 1913

39. McDonough JW, Gruenloh TJ: A comparison of endoscopic and open carpal tunnel release. Wis Med J 92:675-677, 1993

40. Menon J: Endoscopic carpal tunnel release: preliminary report. Arthroscopy 10:31-38, 1994

41. Menon J: Endoscopic carpal tunnel release, a single portal technique. Contemp Orthop 26:109-116, 1993

42. Murphy RX Jr, Jennings JF, Wukich DK: Major neurovascular complications of endoscopic carpal tunnel release. J Hand Surg (Am) 19:114-118, 1994

43. Nagle DJ, Fischer TJ, Harris GD, et al: A multicenter prospective review of 640 endoscopic carpal tunnel releases using the transbursal and extrabursal Chow techniques. Arthroscopy 12:139-143, 1996

44. Nath RK, Mackinnon SE, Weeks PM: Ulnar nerve transection as a complication of two-portal endoscopic carpal tunnel release: a case report. J Hand Surg (Am) 18:896-898, 1993

45. Okutsu I, Hamanaka I, Ninomiya S, et al: Results of endoscopic management of carpal-tunnel syndrome in long-term haemodialysis versus idiopathic patients. Nephrol Dial Transplant 8:1110-1114, 1993

46. Okutsu I, Ninomiya S, Hamanaka I, et al: Measurement of pressure in the carpal canal before and after endoscopic management of carpal tunnel syndrome. J Bone Joint Surg (Am) 71:679-683, 1989

47. Okutsu I, Ninomiya S, Natsuyama M, et al: [Subcutaneous operation and examination under universal endoscope.] J Jpn Orthop Assoc 61:491-498, 1987 (Jpn)

48. Okutsu I, Ninomiya S, Takatori Y: Results of endoscopic management of carpal tunnel syndrome. Orthop Rev 22:81-87, 1993

49. Okutsu I, Ninomiya S, Takatori Y, et al: Endoscopic management of carpal tunnel syndrome. Arthroscopy 5:11-18, 1989

50. Omer GE Jr: Median nerve compression at the wrist. Hand Clin 8:317-324, 1992

51. Paget J: Lectures on Surgical Pathology: Delivered at the Royal College of Surgeons of England. Philadelphia: Lindsay \& Blakiston, 1854, p 42 
52. Paine KWE, Polyzoidis KS: Carpal tunnel syndrome. Decompression using the Paine retinaculotome. J Neurosurg 59:1031-1036, 1983

53. Pagnanelli DM, Barrer SJ: Carpal tunnel syndrome: surgical treatment using the Paine retinaculatome. J Neurosurg 75:77-81, 1991

54. Palmer DH, Paulson JC, Lane-Larsen CL, et al: Endoscopic carpal tunnel release: a comparison of two techniques with open release. Arthroscopy 9:498-508, 1993

55. Phalen GS: The carpal tunnel syndrome. Clinical evaluation of 598 hands. Clin Orthop 83:29-40, 1972

56. Phalen GS: The carpal tunnel syndrome. Seventeen years' experience in diagnosis and treatment of six hundred fifty-four hands. J Bone Joint Surg (Am) 48:211-228, 1966

57. Phalen GS: Reflections on 21 years' experience with the carpal-tunnel syndrome. JAMA 212:1365-1367, 1970

58. Phalen GS: Spontaneous compression of the median nerve at the wrist. JAMA 145:1128-1133, 1951

59. Phalen GS, Gardner WJ, La Londe AA: Neuropathy of the median nerve due to compression beneath the transverse carpal ligament. J Bone Joint Surg (Am) 32:109-112, 1950

60. Phalen GS, Kendrick JI: Compression neuropathy of the median nerve in the carpal tunnel. JAMA 164:524-530, 1957

61. Putnam JJ: A series of cases of paraesthesia, mainly of the hands, of periodical occurrence, and possibly of vaso-motor origin. Arch Med 4:147-162, 1880

62. Resnick CT, Miller BW: Endoscopic carpal tunnel release using the subligamentous two-portal technique. Contemp Surg 22:269-277, 1991

63. Richman JA, Gelberman RH, Rydevik BL, et al: Carpal tunnel syndrome: morphologic changes after release of the transverse carpal ligament. J Hand Surg (Am) 14:852-857, 1989

64. Roth JH, Richards RS, MacLeod MD: Endoscopic carpal tunnel release. Can J Surg 37:189-193, 1994

65. Rotman MB, Manske PR: Anatomic relationships of an endoscopic carpal tunnel device to surrounding structures. J Hand Surg (Am) 18:442-450, 1993

66. Schenck RR: The role of endoscopic surgery in the treatment of carpal tunnel syndrome. Adv Plast Reconstr Surg 11:17-43, 1995

67. Schwartz JT, Waters PM, Simmons BP: Endoscopic carpal tunnel release: a cadaveric study. Arthroscopy 9:209-213, 1993

68. Scoggin JF, Whipple TL: A potential complication of endoscopic carpal tunnel release. Arthroscopy 8:363-365, 1992

69. Seiler JG III, Barnes K, Gelberman RH, et al: Endoscopic carpal tunnel release: an anatomic study of the two-incision method in human cadavers. J Hand Surg (Am) 17:996-1002, 1992 
70. Skoff HD, Sklar R: Endoscopic median nerve decompression: early experience. Plast Reconstr Surg 94:691-694, 1994

71. Slattery PG: Endoscopic carpal tunnel release. Use of the modified Chow technique in 215 cases. Med J Aust 160:104-107, 1994

72. Viegas SF, Pollard A, Kaminski K: Carpal arch alteration and related clinical status after endoscopic carpal tunnel release. J Hand Surg (Am) 17:1012-1016, 1992

73. Woltman HW: Neuritis associated with acromegaly. Arch Neurol Psychiatry 45:680-682, 1941

74. Worseg AP, Kuzbari R, Korak K, et al: Endoscopic carpal tunnel release using a single-portal system. Br J Plast Surg 49:1-10, 1996

75. Zachary RB: Thenar palsy due to compression of the median nerve in the carpal tunnel. Surg Gynecol Obstet 81:213-217, 1945

Manuscript received May 27, 1997.

Accepted in final form June 10, 1997.

Address reprint requests to: David F. Jimenez, M.D., One Hospital Drive, N521, Columbia, Missouri 65212. email: djimenez@surgery.missouri.edu. 